\title{
COAGULAÇÃO/FLOCULAÇÃO DE SUSPENSÕES RICAS EM ÓXIDOS DE FERRO POR SULFATO DE ALUMÍNIO
}

Claudia Dumans Guedes*, Jomara G. Pereira, Jorge C. de Lena e José Fernando de Paiva

Departamento de Química, Instituto de Ciências Exatas e Biológicas, Universidade Federal de Ouro Preto, 35400-000 Ouro Preto - MG

Rosa Malena F. Lima

Departamento de Engenharia de Minas, Escola de Minas, Universidade Federal de Ouro Preto, 35400-000 Ouro Preto - MG

Recebido em 8/9/03; aceito em 11/3/04; publicado na web em 19/7/04

\begin{abstract}
COAGULATION/FLOCCULATION OF SUSPENSIONS OF IRON OXIDE PARTICLES BY ALUMINUM SULPHATE. The destabilization mechanism of suspensions of positively charged iron oxide particles by aluminum sulphate was investigated, aiming to evaluate the efficiency of the latter as a coagulant for natural surface waters from iron ore mining plants. Synthetic waters that simulate natural suspensions were used. The best coagulant dosage was found to be $100 \mathrm{mg} / \mathrm{L}$ at $\mathrm{pH}$. The specific adsorption of hydrolysis products of aluminum salts on iron oxide particles and heterocoagulation processes involving differently charged substrates are proposed to explain the turbidity reduction of the suspensions.
\end{abstract}

Keywords: iron oxide particles; destabilization of suspensions; aluminum sulphate.

\section{INTRODUÇÃO}

As águas superficiais naturais contêm sólidos inorgânicos suspensos ou coloidais, material orgânico em solução, microorganismos e outras impurezas que, em virtude da mútua repulsão das cargas elétricas em sua superfície, se mantêm em suspensão estável por longos períodos de tempo ${ }^{1}$.

No caso de suspensões naturais ricas em óxidos de ferro têm-se cargas que resultam da ionização, na presença de água ou umidade atmosférica, de grupos hidroxila que formam uma monocamada em sua superfície. De um ponto de vista estrutural, a tendência a satisfazer a coordenação dos íons da superfície é responsável pela quimissorção da água que resulta na sua dissociação ou combinação posterior. Os grupos hidroxila superficiais apresentam estereoquímicas diferentes e não se comportam da mesma forma que aqueles da matriz mineral ${ }^{2}$.

O óxido-hidróxido de ferro, a goetita $(\alpha-\mathrm{FeOOH})$, é o mineral de ferro mais abundante e constitui a forma termodinamicamente mais estável entre os óxidos de ferro. Este mineral apresenta uma estrutura cristalina definida, é encontrado de forma disseminada na natureza, independente do clima, e pode ser facilmente sintetizada em laboratório. Na superfície deste mineral observa-se a presença de três tipos de hidroxila - A, B e C. A hidroxila do tipo A, tem origem em um íon oxigênio coordenado a apenas um íon $\mathrm{Fe}^{3+}$ da matriz mineral que foi protonado em virtude de sua exposição à superfície. Em condições ácidas estes grupos adsorvem prótons, formando $\mathrm{FeO}(\mathrm{OH}) . \mathrm{H}^{+}$ou espécies $\equiv \mathrm{FeOH}_{2}^{+}$superficiais que podem participar de reações de complexação com troca de ligantes, dando origem a complexos de esfera interna. Em meio fortemente básico um próton pode ser perdido destes grupos, resultando em sítios $\equiv \mathrm{FeO}^{-}$superficiais. As hidroxilas dos tipos $\mathrm{B}$ e C, menos reativas, têm a mesma origem e encontramse coordenadas, respectivamente, a dois e três íons $\mathrm{Fe}^{3+}$ imediatamente abaixo da superfície ${ }^{3}$. Em goetitas de grande área superficial (maior que $100 \mathrm{~m}^{2} / \mathrm{g}$ ) existem aproximadamente $410 \mu \mathrm{mol} \mathrm{g}{ }^{-1} \mathrm{de}$

*e-mail: claudiaguedes@email.com hidroxilas dos tipos A,B e C, e $220 \mu \mathrm{mol} \mathrm{g}^{-1}$ de sítios ácidos de Lewis. A carga superficial $\left(\sigma_{\mathrm{o}}\right)$ de um óxido metálico resulta, portanto, de equilíbrios ácido-base e depende do $\mathrm{pH}$ e da força iônica do meio ${ }^{4}$.

Uma característica da superfície de um óxido é o seu ponto de carga nula (PCZ). Este ponto é caracterizado pelo valor de $\mathrm{pH}$ do meio para o qual a carga superficial se anula; para um valor de $\mathrm{pH}$ menor que o $\mathrm{PCZ}$ a carga é positiva, e para um valor de $\mathrm{pH}$ maior que o PCZ, é negativa. Freqüentemente o termo IEP (ponto isoelétrico) também é empregado na literatura para designar condições de carga nula sobre partículas coloidais. No entanto, os dois termos traduzem conceitos diferentes. O IEP representa o $\mathrm{pH}$ no qual cargas positivas e negativas da superfície se anulam. O PCZ corresponde à ausência de cargas. A diferença entre eles reside no número de sítios ionizados quando a carga se anula, ou seja, na força relativa dos ácidos $\mathrm{MOH}$ e $\mathrm{MOH}_{2}^{+}$e das bases $\mathrm{MOH}$ e $\mathrm{MO}$. No caso dos óxidos de ferro, a fração de sítios ionizados é pequena e a utilização do termo PCZ é mais adequada ${ }^{4}$.

As interações entre as espécies adsorvidas e grupos hidroxila superficiais, protonados ou não, levam à formação de complexos que modificam a carga resultante das partículas e, portanto, as condições de estabilidade das suspensões. Quando os complexos resultam de forças de atração não específicas, de natureza eletrostática, tem-se a fisissorção. Neste tipo de interação não há modificação da esfera de coordenação das espécies adsorvidas e os complexos são denominados de esfera externa. No caso de cátions facilmente hidrolisáveis, como o $\mathrm{Al}(\mathrm{III})$, estes apresentam uma grande afinidade pela superfície dos óxidos e sua adsorção pode ocorrer mesmo em valores de $\mathrm{pH}$ inferiores ao PCZ do óxido, ou seja, em condições desfavoráveis às interações eletrostáticas. Este processo pode se dar por adsorção de complexos metálicos previamente hidrolisados ${ }^{4} \mathrm{ou}$ por adsorção e posterior hidrólise. A penetração da esfera de coordenação do cátion pelos ligantes oxo ou hidroxo da superfície leva então a um processo de quimissorção e à formação de complexos de esfera interna ${ }^{6}$.

A possibilidade de coagulação entre partículas de óxidos de ferro e partículas de outra natureza, de diferentes cargas e dimensões, também pode ocorrer, e denomina-se heterocoagulação. O processo é observado entre solos e argilas. Cornell e Schwertmann² relatam 
uma experiência em que quantidades crescentes de goetita, com área superficial igual a $51 \mathrm{~m}^{2} / \mathrm{g}$, foram adicionadas à caulinita, em diferentes condições de $\mathrm{pH}$, provocando o aumento do ponto isoelétrico da mistura de um valor de $\mathrm{pH}$ inferior a 2 até acima de 6, IEP da goetita pura. Foram acrescentados teores crescentes de goetita que variaram de 0 a $178 \mathrm{mg}$ por grama de caulinita. Segundo os autores este fato sugere uma íntima associação entre as duas fases, levando gradualmente de uma superfície originalmente carregada negativamente a uma superfície dotada de carga positiva.

De forma geral, a coagulação do material finamente dividido disperso em suspensões naturais é afetada por propriedades da água, tais como temperatura, alcalinidade, COT (carbono orgânico total) e $\mathrm{pH}$, por parâmetros operacionais que afetam as condições hidrodinâmicas do meio, e pela presença e natureza do agente coagulante e sua dosagem. As partículas desestabilizadas pela ação do coagulante podem se agregar em flocos, por meio de mecanismos de transporte, tais como o movimento Browniano, a força da gravidade ou a convecção forçada do fluido ${ }^{7}$.

Atualmente, os floculantes químicos mais empregados no tratamento de água são sais de ferro, $\mathrm{Fe}_{2}\left(\mathrm{SO}_{4}\right)_{3}$ e $\mathrm{FeCl}_{3}$, ou alumínio, $\mathrm{Al}_{2}\left(\mathrm{SO}_{4}\right)_{3}$ (alumen), WAC (cloro-sulfato de alumínio parcialmente hidrolisado) e o mais amplamente utilizado é o PAC (policloreto básico de alumínio $)^{8,9}$. Neste trabalho o sulfato de alumínio foi empregado como coagulante, em vista de sua reconhecida eficácia em estações de tratamento de águas.

As reações de hidrólise do íon alumínio têm sido amplamente estudadas com o objetivo de se esclarecer os mecanismos que regem a coagulação de águas de precipitação pluvial que escoam sobre solos agricultáveis (partículas argilosas de cargas negativas), visando sua utilização para abastecimento público ${ }^{10}$. Nestes estudos ficou clara a preponderância do papel de espécies tais como $\left[\mathrm{Al}_{6}(\mathrm{OH})_{15}\right]^{3+}$, $\left[\mathrm{Al}_{8}(\mathrm{OH})_{20}\right]^{4+},\left[\mathrm{Al}_{54}(\mathrm{OH})_{144}\right]^{18+}, \mathrm{e} \mathrm{AlO}_{4} \mathrm{Al}_{12}\left(\mathrm{H}_{2} \mathrm{O}\right)_{12}(\mathrm{OH})_{24}{ }^{7+}$ sobre o dos íons $\mathrm{Al}^{3+}$.

Para as suspensões ricas em partículas de óxidos de ferro, carregadas positivamente nas condições naturais de $\mathrm{pH}$, os mecanismos de desestabilização permanecem pouco claros.

Este trabalho tem como objetivos a avaliação do coagulante sulfato de alumínio como redutor de turbidez de suspensões ricas em óxidos de ferro, assim como uma investigação dos fenômenos de superfície associados à coagulação/floculação destas suspensões. Packham ${ }^{11}$, trabalhando com sulfato de alumínio em condições de pH controlado, mostrou que o comportamento dos sólidos suspensos em rios é muito semelhante ao dos minerais puros constituintes dos sedimentos. Assim é que, neste trabalho, utilizam-se suspensões sintéticas formadas por associação de minerais puros, vistas como um modelo para estudo de suspensões naturais. Objetiva-se ainda estabelecer as condições ótimas de clarificação, propondo um modelo matemático baseado na resposta e nos parâmetros operacionais do sistema. Para esta tarefa foi empregado o programa Minitab V:13.12 da Minitab Inc.

\section{PARTE EXPERIMENTAL}

As suspensões sintéticas, compostas principalmente por óxidos de ferro, simulam as águas pluviais superficiais que lavam as encostas, taludes, pátios e estradas de companhias mineradoras de ferro, na forma de uma enxurrada lamacenta, de coloração avermelhada. Visando reproduzir o mais fielmente possível a suspensão natural, a caracterização dos sólidos foi realizada por difração de Raios-X, análise termogravimétrica, análise por via úmida e granulometria a laser; as propriedades físico-químicas da água natural foram avaliadas por medidas de $\mathrm{pH}$, oxigênio dissolvido, alcalinidade, condutividade, Eh e sólidos totais. As partículas em suspensão fo- ram caracterizadas quanto à área superficial específica, densidade e porosidade por adsorção de nitrogênio pelo método BET ${ }^{2,3}$. Os minerais hematita, goetita, caulinita e quartzo, que compõem o sedimento sintético, foram isoladamente submetidos à difração de Raios-X (Difratômetro RIGAKU, modelo D-MAX/ B Séries, tubo de cobre, método do pó) para confirmação de estrutura. As suspensões foram preparadas adicionando-se a um determinado volume de água destilada os minerais nas mesmas proporções em que são encontrados em amostras naturais. Assim, os teores de goetita-hematita foram mantidos numa relação de aproximadamente 2:1 (goetita-55\%, hematita-27\%), e teores de caulinita e quartzo correspondendo a cerca de $18 \%$ da massa total (caulinita-12\% e quartzo-6\%). A granulometria dos componentes foi definida de forma a se ter partículas com diâmetro inferior a $38 \mu \mathrm{m}$; para tanto, todas as amostras minerais que compõem o sedimento sintético passaram preliminarmente por uma peneira de 400 mesh. Os minerais foram pesados separadamente em balança analítica, nas proporções pré-estabelecidas, de forma a constituir uma suspensão $1 \%$ (p/v) e misturados em almofariz. A mistura sólida resultante foi submetida a quarteamento e, em seguida, pesada. Dois quilogramas do sólido foram adicionados, sob agitação, a um volume de $200 \mathrm{~L}$ de água destilada. O material foi mantido sob agitação durante $2 \mathrm{~h}$ e, em seguida, analisado quanto à alcalinidade, pH (pH - Meter CG-867, Schott Gerate), turbidez (Photometer SQ118, Merck) e condutividade (condutivímetro Methrom, modelo E527). A determinação do PCZ do sedimento sintético e dos minerais separadamente utilizou o método de Mullar e Roberts ${ }^{12}$. As medidas eletroforéticas de Potencial Zeta e Mobilidade Eletroforética (Zeta Potential Analyser Micromeritics, Model 1202) utilizaram suspensões contendo $5,7 \%$ em peso de sólidos totais.

Como coagulante empregou-se uma solução estoque $(1 \% \mathrm{p} / \mathrm{v})$ de sulfato de alumínio P.A. $\mathrm{Al}_{2}(\mathrm{SO} 4)_{3}\left(14\right.$ a $18 \mathrm{H}_{2} \mathrm{O}-$ marca Cinética), preparada com antecedência de $24 \mathrm{~h}$ em relação ao momento de sua utilização, visando uniformizar eventuais efeitos de "envelhecimento" do sal de alumínio sobre seu efeito coagulante ${ }^{13}$. Os ensaios de coagulação/floculação seguiram o procedimento tradicional de "JarTest” (Jar-Test Milan, modelo JT 101), com 6 jarros, agitação rápida de $120 \mathrm{rpm}$ durante $2 \mathrm{~min}$, seguida de etapa lenta com velocidade de $20 \mathrm{rpm}$ durante 20 min e tempo de sedimentação de 2 h. Foram adicionadas dosagens crescentes de sulfato de alumínio a volumes de $500 \mathrm{~mL}$ de suspensão contidos nos jarros, em diferentes condições de $\mathrm{pH}$ inicial. Para os ajustes de $\mathrm{pH}$ foram utilizadas soluções de $\mathrm{HNO}_{3}$ e KOH, preparadas com reagentes P.A., marca Pro Analysi.

Após a coagulação, ao final do período de sedimentação, amostras do sobrenadante foram recolhidas a uma profundidade de cerca de $2 \mathrm{~cm}$ a partir da superfície do líquido em repouso. Estas amostras foram caracterizadas quanto ao $\mathrm{pH}$ (pH-Meter Schott Geräte, CG867), à turbidez (photometer Merck, SQ-118) e à condutividade (condutivímetro Methrom, modelo E-527).

$\mathrm{O}$ efeito dos constituintes da suspensão sobre a turbidez final, antes e após a adição de uma mesma dosagem de coagulante, foi investigado. Com este objetivo foram preparadas três suspensões sintéticas diferentes, mantendo a relação entre os teores goetita:hematita semelhante à da suspensão natural, e teores de caulinita ou quartzo variados. A primeira suspensão continha $34 \%$ de hematita e $66 \%$ de goetita; a segunda suspensão $27 \%$ de hematita, $53 \%$ de goetita e $20 \%$ de caulinita e, finalmente, a terceira apresentava $27 \%$ de hematita, $53 \%$ de goetita e $20 \%$ de quartzo.

Visando identificar o mineral responsável pela turbidez persistente da suspensão natural, já que a caulinita é reconhecida como importante agente causador de turbidez, foram realizados testes de sedimentação espontânea da suspensão. Após 24 h de repouso, o sobrenadante foi retirado e seco em estufa a $80^{\circ} \mathrm{C}$. O sedimento resultante foi submetido à difração de Raios-X. 


\section{RESULTADOS E DISCUSSÃO}

A suspensão sintética apresentou alcalinidade de $3,0 \mathrm{mg} / \mathrm{L}$ de $\mathrm{CaCO}_{3}$ e não sofreu adição de agentes alcalinizantes, valor de $\mathrm{pH}$ de 6,70, turbidez inicial da ordem de 2300 NTU e condutividade de $27,45 \mu \mathrm{S} \mathrm{cm} \mathrm{cm}^{-1}$ a $25^{\circ} \mathrm{C}$. A área superficial específica dos sólidos foi $51,1434 \mathrm{~m}^{2} / \mathrm{g}$, sua porosidade de $0,15927 \mathrm{~cm}^{3} / \mathrm{g}$ e a densidade de $3,1225 \mathrm{~g} / \mathrm{cm}^{3}$. O difratograma de Raios-X do sólido suspenso, apresentado na Figura 1, acusou a presença de goetita, hematita e caulinita como principais minerais presentes.

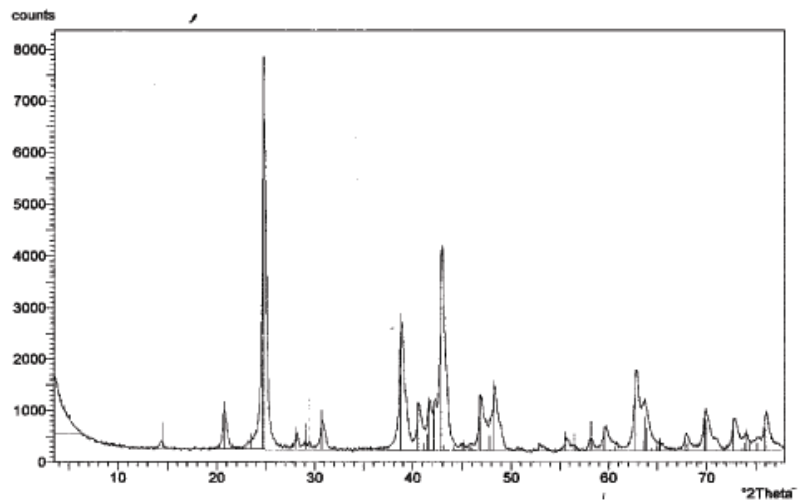

Figura 1. Difratograma de Raios-X do sólido presente na suspensão natural

O difratograma de Raios- $X$ do sedimento resultante da evaporação do sobrenadante, recolhido após 24 h de sedimentação espontânea da suspensão natural, identifica apenas a goetita como sendo o mineral responsável pela turbidez persistente da suspensão. Em vista destes resultados pode-se afirmar que a clarificação da suspensão natural implica essencialmente na desestabilização de partículas de goetita.

Os valores medidos de turbidez final dos sobrenadantes resultantes da adição de diferentes dosagens de coagulante à suspensão sintética sem ajuste prévio de $\mathrm{pH}$, após 2 h de repouso, são mostrados na Figura 2.

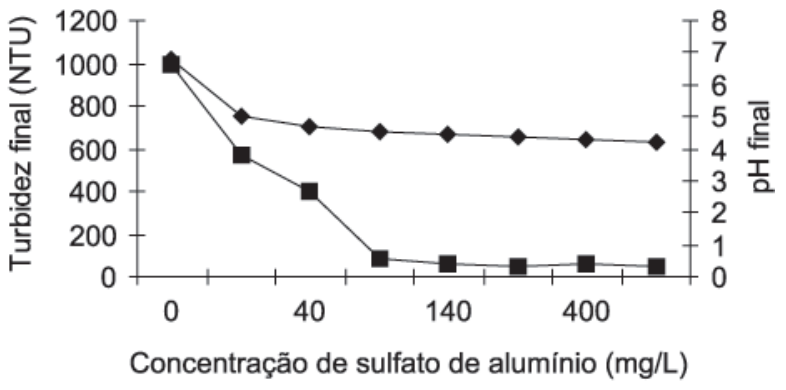

Figura 2. Efeito da dosagem do coagulante sulfato de alumínio sobre a turbidez $(\mathbf{\square})$ e o pH final $(\bullet)$ do sobrenadante após coagulação

Os valores de turbidez final permanecem aproximadamente constantes para concentrações superiores a $100 \mathrm{mg} / \mathrm{L}$. Estes resultados sugerem que concentrações mais elevadas de agente coagulante não trazem nenhum benefício em termos de uma redução efetiva de turbidez. Além desta constatação, observa-se o efeito de acidificação do meio com adições crescentes de coagulante. Medidas de condutividade das suspensões tratadas, a $25^{\circ} \mathrm{C}$, revelam ainda que um aumento de dosagem de sulfato de alumínio de 100 para $1000 \mathrm{mg} / \mathrm{L}$ resulta numa elevação da condutividade do sobrenadante de $120 \mu \mathrm{S} \mathrm{cm}$ para $550 \mu \mathrm{S} \mathrm{cm}^{-1}$. A manutenção dos valores de turbidez para altas concentrações de coagulante permite concluir que não ocorreu reestabilização da suspensão e que, portanto, as partículas não sofreram reversão de suas cargas superficiais.

A Figura 3 mostra a variação de turbidez final da água tratada para diferentes concentrações de sulfato de alumínio em função do $\mathrm{pH}$ inicial ajustado com $\mathrm{HNO}_{3}$ ou $\mathrm{KOH}$.

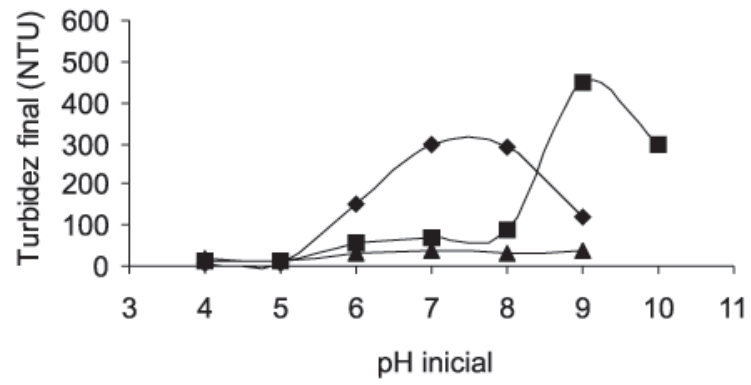

Figura 3. Efeito do pH inicial sobre a Turbidez em diferentes concentrações $(\diamond 10 \mathrm{mg} / \mathrm{L} ; 100 \mathrm{mg} / \mathrm{L} ; \mathbf{\Delta} 1000 \mathrm{mg} / \mathrm{L})$ do coagulante sulfato de alumínio

Concentrações elevadas (1000 mg/L) resultam numa faixa de $\mathrm{pH}$ de coagulação eficiente que vai de 4 a 9 . Na medida em que a dosagem de coagulante decresce, a faixa de $\mathrm{pH}$ de coagulação eficaz se estreita, ou seja, para uma concentração de $100 \mathrm{mg} / \mathrm{L}$, tem-se coagulação eficiente entre valores de $\mathrm{pH}$ de 4 a 8 e, quando a dosagem é de $10 \mathrm{mg} / \mathrm{L}$, este intervalo se reduz para pH's de 4 a 5 . Em todas as concentrações estudadas observa-se um ligeiro aumento de turbidez para valores de $\mathrm{pH}$ superiores a cinco. Isto sugere uma mudança de mecanismo de reação, provavelmente em consequiência de mudanças na especiação do alumínio nesta faixa de $\mathrm{pH}$. Para valores de $\mathrm{pH}$ inferiores a 5 os poliidroxocomplexos catiônicos de alumínio constituem as espécies predominantes; para valores de $\mathrm{pH}$ compreendidos entre 5 e 8 observa-se a formação preferencial do hidróxido de alumínio e, para valores superiores a 9, um enriquecimento do meio em hidroxocomplexos de Al(III) de carga negativa ${ }^{10}$. Portanto, numa faixa ácida de $\mathrm{pH}$, na qual predominam espécies positivas de alumínio, a redução de turbidez observada não se deve a interações de natureza eletrostática. A desestabilização da suspensão pode estar associada à adsorção por complexação de poliidroxocomplexos catiônicos sobre a superfície das partículas carregadas positivamente.

Por outro lado, deveria ser levada em conta a possibilidade da adsorção de íons sulfato sobre os óxidos de ferro. No entanto, estudos sobre a adsorção de ânions sobre a superfície da goetita demonstram que a adsorção específica deste íon em condições ácidas ( $\mathrm{pH}$ em torno de 4,0) é desprezível ${ }^{2,5}$.

A Figura 4 mostra a diferença $\Delta \mathrm{pH}$ entre valores de $\mathrm{pH}$ da suspensão antes da adição do sulfato de alumínio (pH inicial) e aqueles após a adição de coagulante ( $\mathrm{pH}$ final), em função do $\mathrm{pH}$ inicial ajustado com $\mathrm{HNO}_{3}$ ou $\mathrm{KOH}$, para diferentes concentrações (10, 100 e 1000 $\mathrm{mg} / \mathrm{L}$ ) do eletrólito sulfato de alumínio. A figura mostra, ainda, a evolução dos valores de $\Delta \mathrm{pH}$ em função do $\mathrm{pH}$ inicial, na presença de um eletrólito indiferente $\left(\mathrm{KNO}_{3}\right)$ e na ausência de sulfato de alumínio.

Observa-se um deslocamento do ponto de interseção das retas relativas às várias concentrações de coagulante adicionado $(10,100$ e $1000 \mathrm{mg} / \mathrm{L}$ ) com o eixo dos pH's, em direção a valores de $\mathrm{pH}$ cada vez mais baixos. Os pontos de interseção, por analogia à metodologia de Mullar e Roberts ${ }^{12}$ para determinação de PZC's de óxidos de ferro, correspondem aos PZC's dos agregados formados, nas diferentes condições de força iônica estudadas. Este tipo de deslocamento, na presença de espécies que sofrem quimissorção, é uma evidência de adsorção específica de cátions ${ }^{3,14}$. Esta observação, juntamente com a informação do diagrama de estabilidade do alumínio em solução ${ }^{10}$, 


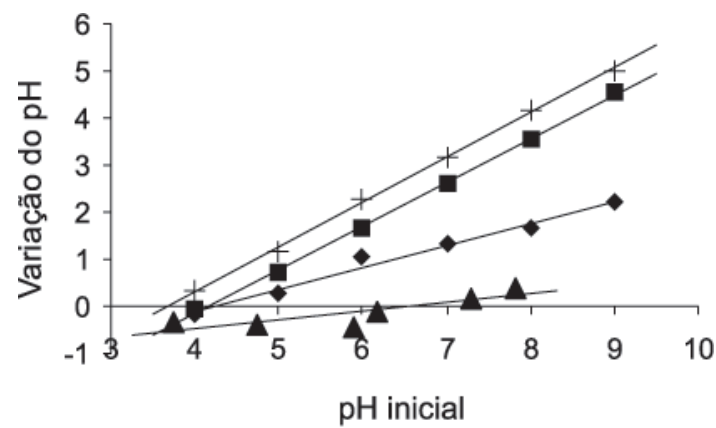

Figura 4. Efeito de diferentes concentrações de eletrólito $(\downarrow 10 \mathrm{mg} / \mathrm{L}$; $\mathbf{\square} 100 \mathrm{mg} / \mathrm{L} ;+1000 \mathrm{mg} / \mathrm{L} ; \mathbf{\Delta}$ sem sulfato) sobre o pH final da suspensão para diferentes valores de $\mathrm{pH}$ inicial

de que nestas condições predominam hidroxocomplexos catiônicos, contribui para a hipótese de complexação superficial destas espécies sobre as partículas de óxido, afetando sua carga superficial pela formação de complexos de esfera interna.

Por outro lado, levando em conta a composição mineralógica do sedimento sintético, assim como os minerais puros, os valores de PZC determinados reproduziram aqueles relatados na literatura, como mostra a Tabela 1.

Tabela 1. Valores medidos de PZC utilizando método eletrocinético (Potencial Zeta) e polpa contendo 5,7\% de sólidos

\begin{tabular}{lll}
\hline Mineral & PZC & Valores de referência ${ }^{2-4,15}$ \\
\hline Caulinita & 4,0 & 4,$7 ; 2-4,6$ \\
Goetita & 7,0 & $6,1 \pm 0,6 ; 7,4-9,5 ; 7,0 ; 5,9-6,7$ \\
Hematita & 7,1 & 7,$0 ; 7,2 ; 9,3 ; 9,4 ; 8,5 ; 4,2-6,9$ \\
Quartzo & 2,0 & $2,0 \pm 0,3 ; 1-3$ \\
Sedimento sintético & 6,1 & \\
\hline
\end{tabular}

O PZC do sedimento sintético reflete a participação de cada um dos constituintes da mistura. Seu valor, medido experimentalmente, aproxima-se razoavelmente do valor calculado segundo uma média ponderal dos PZC's dos minerais, de acordo com sua participação na mistura $(0,55 \times 7,0+0,27 \times 7,1+0,12 \times 4,0+0,06 \times 2,0=6,4)$. Apesar deste cálculo ser simplista, por não levar em conta as áreas superficiais específicas dos diferentes constituintes do sólido suspenso, ele sugere uma associação íntima entre os minerais, como previsto por Cornell e Schwertmann².

Numa tentativa de investigar a possível participação das partículas de carga superficial negativa em um processo de heterocoagulação, foi estudado o efeito dos constituintes da suspensão sintética sobre a redução da turbidez. Para este fim, foram preparadas suspensões sintéticas de composições variadas, como mostra a Tabela 2. Observase que a turbidez final após coagulação da suspensão constituída apenas por partículas de carga positiva, hematita e goetita, é quase três vezes superior aos valores da turbidez final das suspensões que contém algum tipo de partícula negativa (quartzo ou caulinita) nas condições de $\mathrm{pH}$ inicial igual a 6,5.

Os resultados apresentados reforçam a idéia de um mecanismo envolvendo a associação entre substratos de cargas opostas ${ }^{5,16}$.

Em vista do exposto, e considerando ainda que a coagulação é mais efetiva para valores de $\mathrm{pH}$ em torno de 4,0 , é provável que partículas negativas de quartzo participem do mecanismo de coagulação através de uma etapa de heterocoagulação.

Finalmente, medidas de mobilidade eletroforética da suspensão, em pH 4,0, após a adição de uma dosagem de sulfato de alumínio de
Tabela 2. Efeito da constituição da suspensão sobre a redução da turbidez respectiva, após a adição de 100 ppm de coagulante, em pH igual a 6,50

\begin{tabular}{lccc}
\hline & \multicolumn{3}{c}{ Constituição da suspensão } \\
& $\begin{array}{c}\text { Hematita }+ \\
\text { Goetita } \\
\text { Gematita }+ \\
\text { Goetita }+ \\
\text { Caulinita }\end{array}$ & $\begin{array}{c}\text { Hematita }+ \\
\text { Quartzo }\end{array}$ \\
\hline pH inicial & 6,60 & 6,70 & 5,50 \\
Turbidez inicial (NTU) & 1970 & 1850 & 1750 \\
Turbidez final(NTU) & 925 & 350 & 330 \\
Redução de Turbidez (\%) & 53 & 81 & 81 \\
\hline
\end{tabular}

$100 \mathrm{mg} / \mathrm{L}$, forneceram valores positivos de cerca de $7,5 \times 10^{-5} \mathrm{~cm}^{2} \mathrm{~V}^{-1} \mathrm{~s}^{-1}$. Nestas condições favoráveis à coagulação, portanto, a carga média resultante das partículas dispersas é positiva. Este resultado permite mais uma vez supor que o mecanismo de coagulação predominante não é de neutralização de cargas.

Duas possibilidades podem ser propostas para analisar o comportamento do sistema estudado frente à adição do agente coagulante sulfato de alumínio. A primeira contemplaria um processo de heterocoagulação entre partículas de óxido carregadas positivamente e partículas de quartzo, resultando num agregado de carga final negativa; este agregado aniônico seria neutralizado em parte pelos hidroxocomplexos de carga positiva predominantes nas condições de $\mathrm{pH}$ do meio. A segunda possibilidade se basearia na formação de complexos superficiais de carga positiva resultantes da adsorção dos hidroxocomplexos de alumínio sobre a superfície das partículas de óxidos de ferro. Estes complexos catiônicos interagiriam numa segunda etapa de heterocoagulação com partículas negativas de quartzo, provocando sua sedimentação. As evidências experimentais reforçam a segunda proposta.

\section{Otimização}

Visando determinar as condições ótimas de clarificação destas suspensões, foi proposto um modelo matemático utilizando a turbidez final (T) como resposta e o pH e o logaritmo decimal da dosagem de coagulante $(\log \mathrm{D})$ como parâmetros. O procedimento de regressão múltipla conduziu à equação abaixo:

$\mathrm{T}=19,8(\log \mathrm{D})^{2}-5,1(\mathrm{pH})^{2}-21 \mathrm{pH} . \log \mathrm{D}+126,1 \mathrm{pH}-337,8$

cujo coeficiente de correlação $\left(\mathrm{r}^{2}\right)$ é igual a 0,943 , o que demonstra a adequação do modelo. Com base nesta equação obtém-se a superfície de resposta apresentada na Figura 5.

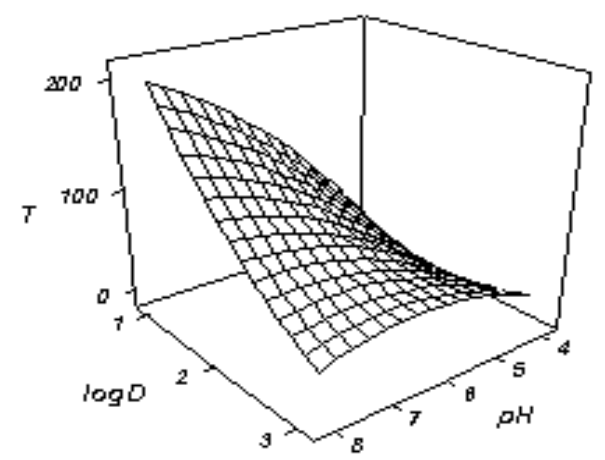

Figura 5. Superfície de resposta mostrando as condições otimizadas de trabalho 
Observa-se que para valores baixos de $\mathrm{pH}$ a eficiência da coagulação é mais satisfatória. O estudo dos pontos críticos para a equação, com pH fixado em 4, conduz a um valor mínimo de turbidez final para uma dosagem de coagulante de $132 \mathrm{mg} / \mathrm{L}$. A Figura 6 mostra a projeção desta superfície sobre o plano T.log D.

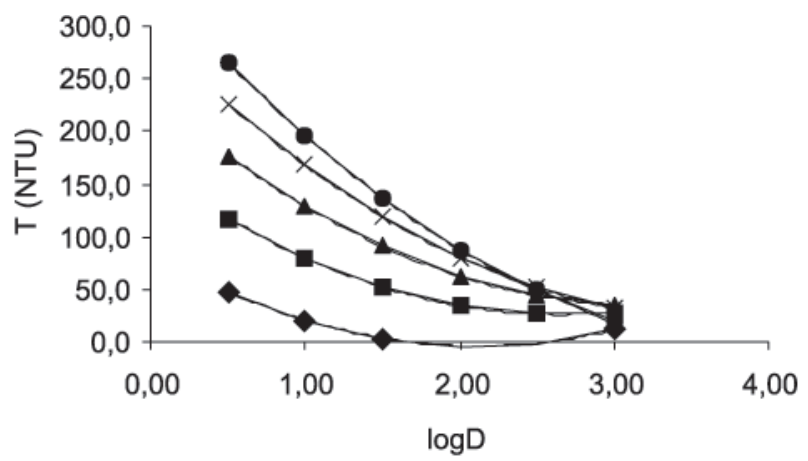

Figura 6. Projeção da superfície de resposta sobre o plano T. $\log D(\diamond p H$ 4,0; $\mathbf{\square H}$ 5,0; $\mathbf{\Delta} \mathrm{pH} \mathrm{6,0; \times pH} \mathrm{7,0;-} \mathrm{pH} \mathrm{8,0)}$

A Figura 6 permite constatar que para um $\mathrm{pH}$ igual a 4, o mínimo de turbidez ocorre para um valor de $\log \mathrm{D}$ de aproximadamente 2, ou seja, para cerca de $100 \mathrm{mg} / \mathrm{L}$ de coagulante.

\section{CONCLUSÕES}

As melhores condições de coagulação da suspensão sintética de óxidos de ferro, utilizando o sulfato de alumínio como coagulante, na ausência de agente alcalinizante, ocorrem em valores de $\mathrm{pH}$ em torno de 4,0 e uma dosagem de coagulante de aproximadamente $100 \mathrm{mg} / \mathrm{L}$.

O modelo de otimização adotado mostrou uma boa adequação ao sistema experimental, e definiu uma concentração ótima de coagulante de $132 \mathrm{mg} / \mathrm{L}$ para um valor de $\mathrm{pH}$ igual a 4 .

Nestas condições de $\mathrm{pH}$, as espécies de $\mathrm{Al}$ predominantes em meio aquoso são hidroxocomplexos de carga positiva. As partículas de óxidos de ferro que constituem a suspensão sintética estão abaixo de seu PZC, portanto, estão também carregadas positivamente. Logo, um mecanismo de adsorção via interação eletrostática entre as duas espécies, sem a participação de outras partículas eletricamente carregadas presentes, é inviável.

Os ensaios com suspensões sintéticas de composições diferentes evidenciaram que partículas de carga negativa podem desempenhar um papel no processo de coagulação. Em pH 4,0, PZC da caulinita, as partículas de quartzo constituem as espécies negativas predominantes no meio.

As evidências experimentais que reforçam a hipótese de adsorção de cátions sobre as partículas de óxidos de ferro, permitem concluir que provavelmente hidroxocomplexos de alumínio de carga positiva são adsorvidos especificamente sobre a superfície das partículas. Este fenômeno cria condições para interações eletrostáticas entre as espécies formadas e as partículas de quartzo presentes.

Propõe-se, portanto, que o mecanismo de coagulação das partículas de óxido de ferro compreende uma primeira etapa de adsorção específica de hidroxocomplexos catiônicos, seguida de uma etapa de heterocoagulação.

\section{AGRADECIMENTOS}

Os autores agradecem às empresas Samarco SA e Companhia Vale do Rio Doce (mina de Alegria), através de suas Gerências de Meio Ambiente, por terem fornecido as amostras da suspensão natural utilizada neste trabalho. Ao CNPq e à UFOP pela bolsa de iniciação científica de J. G. Pereira.

\section{REFERÊNCIAS}

1. Filella, M.; Colloids Surf., A 1993, 73, 255

2. Cornel, R. M.; Schwertmann, U.; The Iron Oxides, VHC Publishers: New York, 1996.

3. Sposito, G.; The surface chemistry of soils, Oxford University Press: New York, 1984.

4. Parfitt, R. L.; Atkinson, R.; Nature 1976, 264, 740.

5. Beckett, R.; Surface Colloid Chemistry in Natural Waters and Water Treatment, Plenum Press: New York, 1990.

6. Jolivet, J. P.; De la solution à l'oxyde, Savoirs Actuels InterÉditions /CNRS Éditions: Paris, 1994.

7. Mendes, C. G. N.; Tese de Doutorado, Escola de Engenharia de São Carlos, Universidade de São Paulo, Brasil, 1989.

8. Masion, A.; Tese de Doutorado, Institut National Polytéchnique de Lorraine, França, 1993.

9. Okuda, T.; Baes, A.; Nishijima W.; Okuda, M.; Water Res. 2001, 35, 405.

10. DiBernardo, L.; Métodos e Técnicas de Tratamento de Água, ABES: Rio de Janeiro, 1993.

11. Packham, R. F.; J. Appl. Chem. 1962, 12, 556.

12. Mullar, A. L.; Roberts, R.; CIM Transactions 1966, vol. LXIX, p. 438.

13. François, R. J.; Water Res. 1987, 21, 523.

14. Lyklema, J.; Fleer, G. F.; Colloids Surf. 1987, 25, 357.

15. Langmuir, D.; Aqueous Environmental Chemistry, Prentice Hall: New Jersey, 1997.

16. Klein, B.; Hallbom, D. R.; Rheopectic Properties of Nickel Laterite Suspensions, Short Course; University of British Columbia:Vancouver, 2002. 